\title{
Networked interactive whiteboards: Rationale, affordances and new pedagogies for regional Australian higher education
}

\begin{abstract}
Phillip Dawson
Deakin University

This article presents an argument for the use of networked interactive whiteboards (NIWBs) in regional Australian higher education and identifies new pedagogies for this context. Most Australian universities operate multiple campuses, and many use video conference facilities to deliver courses across these sites. For students at remote video conference sites, their classroom experience is often one of isolation and limited student to student contact. In this article, NIWBs are proposed as a tool to enhance this mode of delivery and exploratory research into the additional affordances they provide is presented. By using networking with IWBs, annotation and gesture can be shared across distances. Emerging possibilities from the integration of NIWBs with video conference, web conference and lecture capture systems are also explored. Three new pedagogies for regional Australian higher education are proposed based on these new capabilities.
\end{abstract}

\section{Introduction}

The Australian higher education sector has been given the responsibility to significantly increase the proportion of young Australians with bachelor degrees or higher by 2025 to $40 \%$ of 25-34 year olds (Commonwealth of Australia, 2009). In order to achieve these targets, higher education participation rates for young people from rural and regional areas will need to increase (Bradley, Noonan, Nugent \& Scales, 2008). Networked interactive white boards (NIWBs) are one tool that can help achieve this goal through enhancing multi-site course delivery.

This paper presents an argument for the use of NIWBs in regional higher education. This argument is based on exploratory research and informed by theoretical and empirical literature. Firstly the challenges of course provision at regional campuses and education access centres are discussed to provide a context for the discussion of NIWBs. The possible actions facilitated by IWBs and NIWBs are then discussed as identified from exploratory research. Three adaptations of existing higher education pedagogies are then proposed. This work is framed in the context of the Deakin at Your Doorstep (D@YD) project, which is an A\$8.2 million Australian Government funded initiative by Deakin University to extend access to higher education to an increased number of regional centres.

\section{Higher education in regional Australia}

The experience of Australian regional learners in higher education is somewhat different to that of their urban peers. For some regional learners, their experiences of 
postsecondary education are limited if they do not go online (Kilpatrick \& Bound, 2003). Other regional learners are located at smaller campuses of multi-campus institutions, and their participation in education is also often mediated by technology. The student experience through technologies such as video conferencing can be isolating and lack peer to peer interaction (Knipe \& Lee, 2002; Saw, et al., 2008; Worthy, Arul, \& Brickell, 2008). Providing access to support services for regional students can be more difficult and costly, a feature that can result in some services not being offered at all. In this section, these factors of the student experience in regional higher education are discussed to give a context for the discussion of NIWBs.

Regional learners have a variety of online learning opportunities available to them, although for underprepared students these can present further challenges. Learners may not yet possess the required technical skills for online study; the assumption that students are literate in the required technology for study by virtue of their age has been the subject of some debate (Bennett, Maton \& Kervin, 2008). In addition to technology literacy, success in online learning demands greater motivation and academic skills (Kilpatrick \& Bound, 2003). For students who lack motivation, or technical or academic skills, online study may be less preferable than face to face study.

For regional learners, face to face university study is typically accessed through a comparatively small satellite campus or education access centre. Most Australian universities teach courses across multiple locations; this feature of higher education was examined by Winchester and Sterk (2006) through a review of Australian Universities Quality Agency (AUQA) audits. Issues of "fragmentation, duplication, inconsistency and inequitability over a range of areas of activity" (p. 164) were found. Absent from Winchester and Sterk's work was a discussion of the educational implications of cross-campus teaching; for this we turn to work done in understanding video conference teaching, one of the dominant delivery modes in this field.

In a video conference lecture, students distributed across multiple sites can see and hear each other and through video cameras and screens. Although this interaction occurs in real time and attempts to mimic a face to face lecture, student satisfaction can be lower. Freeman (1998) found that compared with the alternative of delivering face to face lectures at all sites, video conferencing was not considered to be a great improvement:

\begin{abstract}
students and staff felt the lecturing, learning activities and interactions were not improved. They were also slower. Other disadvantages were the time lost through technical difficulties and the greater likelihood for distractions at the remote campus. Students at the remote campus felt disadvantaged despite various preventative strategies. (Freeman, 1998, p. 209)
\end{abstract}

Later work echoes Freeman's finding of disadvantage to students at remote video conference sites, and describes problems of isolation, less time spent on learning, and unsuitable teaching strategies (Knipe \& Lee, 2002; Worthy, et al., 2008). Less peer to peer interaction is reported in some video conference teaching environments when compared with face to face classes (Worthy, et al., 2008; Saw, et al., 2008).

To provide students with peer learning (Topping, 2005) opportunities, many Australian universities have implemented programs such as Peer Assisted Study Sessions (PASS, also known internationally as Supplemental Instruction - SI) on their 
larger campuses (Martin, 2008; Murray, 1999). PASS has been operating in Australia since the 1990s on a small scale and in the 2000s on a larger scale. The program has a track record in improving student success, academic achievement and retention (Martin \& Arendale, 1993; Tinto, 1998). Despite these benefits, it can be a difficult intervention to support in a local, face to face mode across geographically dispersed campuses for quality assurance, administrative and logistical reasons (Dawson, Lockyer \& Ferry, 2007).

Online learning demands skills of regional learners that underprepared students may not have. The dominant synchronous lecture delivery platform, video conference, provides students with a substitute for face to face lectures, but provides little opportunity for peer to peer interaction. It can also be an isolating experience. Local interventions to address issues of social connection and peer learning can be costly and difficult to support. In the next section, networked interactive whiteboards (NIWBs) are proposed as a tool that can be used to address these challenges.

\section{Networked interactive white boards (NIWBs)}

In this paper interactive whiteboards (IWBs) that are connected to other IWBs via computer networks are termed networked interactive whiteboards (NIWBs). This connection is typically through the IWBs being used with computers that are attached to an organisational intranet or the Internet. The affordances of standalone IWBs are investigated here in brief, and followed by the extra set provided by the addition of networking.

One starting point for examining the capabilities of IWBs is by comparing them with familiar classroom tools. In their review of the literature, Glover, Miller, Averis and Door (2005) describe the IWB as similar to a white or black board, but with added functionality from inbuilt programming. Software running on the attached computer allows learners to move on-screen objects or answer questions and receive automated feedback. From a technical perspective these interactions would all be possible with a touchscreen such as those found on smartphones or tablet computers, however the larger scale of the IWB allows for sharing and collaboration. IWBs can also be described as an extension of the data projector, and Glover, et al. (2005) note additional capabilities IWBs provide over that familiar classroom tool. Citing Berque, et al. (2000) they note the possibility for 'overwriting' (writing with markers on top of the onscreen picture) that is not possible with a data projector. One application of overwriting is to provide signalling (Mayer, 2009) to learners. Signalling reduces the amount of mental processing required by providing cues to the learner about what to focus on and how to organise it.

Gesture can be used as another form of guidance in IWB settings, and is discussed by Miller and Glover (2006) in the context of mathematics education. Gesture is understood to be a part of collaborative mathematical problem solving (Reynolds \& Reeve, 2001), and understanding of unfamiliar mathematical concepts (Herbert \& Pierce, 2007). Through video examination of secondary mathematics lessons, Miller and Glover found that IWB lessons incorporated a greater amount of gesture, however this was dependent on the individual teacher. As with the other affordances of IWBs, the tool provides the opportunity for gesture, but the teacher's approach determines if it will be used. 
Some studies indicate that IWBs can increase student motivation, although little of this literature is from a higher education context. The novelty of IWBs, as well as the use of colour and 'hide and reveal' has been found to increase motivation in school based contexts (Glover, et al., 2005), however these gains are often short lived (Moss, et al., 2007, as cited in Higgins, Beauchamp \& Miller, 2007) and may not apply to tertiary students.

The additional interactivity allowed by IWBs does not necessarily translate into more interactivity between students. Higgins, et al. (2007) raise the issue of the contextdependent meanings of the term 'interactive'. Although using IWBs can result in an increased volume of technology interactions, this can come at the cost of reduced student to student interactivity. The different types of interactivity are defined by Higgins et al. as "technical interactive affordances" and "pedagogical interactive affordances" (p. 219). From their review of the literature on IWBs they find that "An IWB may be technically interactive, but may lead to less interactive and more didactic teachings" (p. 219). Somewhat counter-intuitively, less interactive uses of IWBs can lead to more interactions between learners and between learners and teachers (Smith \& Higgins, 2006). Within the context of video conference lectures in regional higher education, the literature reviewed indicates that student-to-student interaction is lacking but necessary for integration, and ultimately, retention. In the next section some of the additional affordances of networked IWBs for interactivity will be discussed.

\section{Additional affordances of NIWBs}

There is minimal research literature about networked interactive whiteboards. Smith, Higgins, Wall and Miller's (2005) review of the literature on IWBs mentions the use of networked computers as repositories for materials to be used with IWBs, however this is not networking in the sense under investigation in this paper. Here, networked IWBs are those that are synchronously connected together through networked computers. Glover et al. (2005) mention that there are many features of IWBs that are mentioned in promotional materials but have not been investigated in the research literature or have had minimal investigation. A literature search found no peerreviewed research that investigated NIWBs, and there was no mention of them in the review articles considered. This lack of literature motivated the design of a research project to identify new affordances and applications of NIWBs.

\section{Research design}

An exploratory research project was undertaken to identify new capabilities and applications of NIWBs. Exploratory research methods are appropriate for this topic due to the lack of research literature in the field and the emergent nature of NIWBs. A number of new possibilities of NIWBs have been identified through experimentation with the tools, informal discussion with technologists, the literature surveyed, and materials provided by IWB vendors.

This investigation forms part of a larger mixed methods multi-case study into a distributed learning community model being developed and evaluated through the Deakin at Your Doorstep project. In the initial phase of the project, classrooms equipped with video conference facilities and NIWBs have been built in the regional Victorian centres of Warrnambool, Bairnsdale, Dandenong and Swan Hill. Teaching in these facilities commenced in March 2010, and data collection through interviews and 
surveys is currently underway at the sites. Preliminary data from this project are not yet available for research ethics reasons; the data used in this article are from the exploratory investigation.

In the next section of this paper, the room design is presented and followed by new affordances identified through the exploratory research project. New pedagogies identified through combining these affordances with existing higher education pedagogies are then discussed.

\section{The Deakin at Your Doorstep classroom design}

The classrooms used for the D@YD project have been purpose designed for networked teaching and learning, with an emphasis on collaboration. Each space is equipped with seating for around 30 students at kidney shaped tables designed to encourage peer learning. At the front of the classroom there is a NIWB as well as a separate projector. There are two video cameras in the space, with one facing the front of the room and the other facing the back. Microphones are on each student's desk, as well as at the lectern at the front of the room. The desk-mounted microphones have a button students can push when they wish to talk, and the video camera is set up to zoom in on students when they speak. The rooms include other facilities including speakers, automatic blinds and document cameras.

The D@YD classrooms can be used for a variety of class types. The most relevant to this discussion are lectures, tutorials and computer labs. During lectures, each site is synchronously connected, with the projector showing video conference feeds from all sites and the NIWB showing materials such as a PowerPoint slideshow. This is similar to a common two-projector video conference configuration where one projector shows video of each site while the other projector shows media such as a PowerPoint presentation. In tutorials and computer laboratory classes the video conference facilities can be disabled and the NIWBs can operate as standalone IWBs.

\section{Findings}

\section{Sharing the IWB experience across distance}

Experimentation has shown that using a NIWB in place of the second projector provides the full suite of IWB tools simultaneously to participants at each site. When used as a second projector for traditional video conference lectures, the teacher is able to annotate their slides during a presentation using computer based tools such as the pen tool in PowerPoint. Using the NIWB takes this teaching technique away from the computer screen and into a public space. The lecturer can interact with the material through gesture and annotation and have this broadcast synchronously across all sites.

\section{Collaborating across sites}

Experimentation has revealed that in addition to using the NIWB to broadcast the content of the lecturer's IWB, the NIWB can be used for student to student interaction across sites. This interaction can take a variety of forms. The students can synchronously share the one space, as if they were all participating in a class with one shared IWB. Using this approach provides the students with an opportunity to collaborate as a large class, however, the technology does not necessarily overcome any reluctance the students may have to talk or contribute to large lectures. 
Another feature of the NIWB revealed through experimentation is the ability of the screen to switch between operating in a local mode and operating in a networked mode. This provides the opportunity for each site to work on a local IWB, and then share it with the other sites.

The two cross-site collaboration affordances provided by NIWBs may address deficiencies in the video conference delivery mode discussed earlier in this paper. By providing a shared space for students to collaborate and a facilitated group process, the technology may increase the amount of student to student interaction, which has been identified as low in video conference environments (Knipe \& Lee, 2002; Saw, et al., 2008; Worthy, et al., 2008). This is currently being investigated in the larger research project.

\section{Integration with lecture capture systems}

Lecture capture systems (also referred to as web based lecture technologies, 'WBLT') provide the ability for an institution to record classes and make them available to students through the Internet; the term 'lecture capture' is used here instead of 'lecture streaming' as students are also allowed to download and save a lecture in its entirety. The lectures held in the D@YD classrooms are recorded and made available to students around 30 minutes after the completion of the class. NIWBs allow for the gestures, annotations and cross-site collaborations described above to be included in this recording. In a traditional video conference lecture capture environment these interactions would be lost. The multi-purpose nature of the space also allows for other sorts of classes, such as tutorials, to use the same recording infrastructure.

\section{Integration with web conferencing systems}

Technologists identified the possibility of integrating web conferencing systems into a video conference NIWB setting to allow off-site students to join classes. The tools provided by web conferencing typically include synchronous video and voice communication as well as screen sharing. These tools operate with minimal setup on a student's personal computer. The NIWB can act as a bridge between a video conference and a web conference. Connecting to a web conferencing session through the NIWB and sharing the screen can make the video conference lecture available in real time to offsite students. Through the web conference, students can see the contents of the NIWB on their home computer screen and participate in the lecture through video or voice communication. They can also have access to the full NIWB toolset, and can draw with their mouse in the same way that their on campus peers can draw with the IWB pen. Students who own compatible, tablet-style devices can use these to write in pen just as their on campus peers do.

In a larger lecture space, the ability to connect to the NIWB via web conferencing could be useful for students who are not able to reach the front of the classroom. Students could view the contents of the NIWB in real time on their laptop or tablet and contribute from where they are sitting in class. This may also provide more equitable participation for students who have impaired mobility or vision. Students and technologists at Deakin University's Warrnambool campus are currently working on developing support materials for the web conference-video conference mode of delivery. 


\section{The challenges posed by NIWBs}

The mode of delivery described here that incorporates NIWBs with video conference has been supported by an Internet bandwidth increase of around 40 megabits per second at each site. Experimentation has found that this amount of bandwidth is sufficient, although significant changes to system configuration were necessary for the content of the NIWBs to be clear. During initial testing, some complaints were received from remote sites that simple PowerPoint slides containing black text on a white background were unclear. After modifications were made to settings this was fixed, however, testing with different types of content may reveal more problems like these.

Another problem posed by the new NIWB classroom context is that of reliability. The NIWB can pose further technical difficulties in addition to those described by Freeman (1998). Designing classes around the integrated use of NIWBs and video conference has meant that when either technology failed at a site, the students at that site could participate in only part of the class. In cases where the NIWB failed at a site, students were left with static print copies of materials. The teacher faces a difficult decision in this circumstance: to continue using the capabilities of the technology, which are available to most students, or to only use the features available to all students.

\section{New pedagogies for NIWBs}

Based on the literature reviewed here and the exploratory research conducted into the affordances of NIWBs, new pedagogies are possible in this environment. One starting point in identifying new higher education pedagogies is as adaptations of existing approaches. Three are detailed below: an enhanced video conference lecture delivery; a bridged video conference-web conference lecture; and a multi-site adaptation of Video Supplemental Instruction and Tutored Video Interaction.

\section{NIWB-enhanced video conference lectures}

The goal of NIWB-enhanced video conference lectures is to address some deficiencies of the two-projector video conference lecture mode of delivery. In this mode of delivery, one projector shows the video conference pictures of all sites, while the other projector shows any visual media the lecturer wishes, typically a slideshow presentation. NIWB-enhanced video conference lectures use the NIWB for the second projector, which allows for gesture and annotation through:

- Highlighting, underlining or circling information to focus the students' attention

- Annotating diagrams and formulae to explain numeracy concepts

- Explaining processes in real time with synchronised annotation, gesture and discussion

- Using on screen tools to control video and annotate frames

This enhanced lecture mode is intended to provide students with experience learning in an environment that is similar to a traditional higher education lecture; students watching the recorded lecture experience this as well. The NIWB provides opportunities for local and inter-site collaboration. A potential inter-site application would be in students explaining how to interpret a particular graph. Using the NIWB the students highlight the graph's axes and show an increasing trend. Using the NIWB in conjunction with video conference, the students' hand movements to demonstrate the increasing gradient of a line could be shown in real time as they write on the board. 
Later, other students viewing the lecture recording are able to review the entire exchange in real time. Being able to view the students, hear their explanations and see their annotations allows them to act as inter-site role models for interpreting the graph. If the NIWB were used for local collaboration at a site, a tutorial-sized group (10-30 students) would work on its own local IWB before sharing with a larger group. An application of this would be preparing for a debate on the use of lecture capture systems. All of the students at one site participate in a brainstorm about the benefits of lecture capture systems, which are then refined by the students into a series of arguments to use in a multi-site debate. They then prepare visual materials, choose speakers, and join the other sites. Each site in turn presents their side of the debate, showing the materials they have just prepared through the NIWB. The ability to isolate the IWB to discuss and prepare materials and then share with the other sites facilitates local and networked peer learning.

The pedagogical approach described here addresses identified deficiencies in video conference lectures, while attempting to model necessary academic skills. Peer learning opportunities are less common in standard video conference lectures (Knipe \& Lee, 2002; Saw, et al., 2008; Worthy, et al., 2008), and the use of the NIWB for local and networked student interactions attempts to address this. Academic skills can be role modelled by the teacher and the students, particularly in relation to understanding visual and text information, which may assist regional students to succeed in online learning. Data are currently being gathered about this mode of delivery to understand its effectiveness.

\section{Bridged video conference and web conference lectures}

Off-campus students can participate in a NIWB-enhanced video conference lecture through the use of web conference technology. Although this is possible with minimal changes to the technology required, experimentation and discussion with technologists have raised new pedagogical challenges. Students attending through web conference from home do not have co-located peers, unlike students at other sites. When other sites are performing local group work, such as in the debate example, online students can either join a site or become a separate group. By creating a separate group for web conference students, they can use the different capabilities of their technology, such as the ability to virtually raise their hand or use text to communicate. Additionally, this allows for students located on campus to engage in a component of fully face to face communication in the middle of a video conference class. On completion of a group activity such as preparing for a debate, web conference students can present their work to the class on the NIWB, albeit lacking some of the components of gesture allowed by using a local IWB.

This new pedagogical approach can extend participation in higher education lectures to students who are not able to physically attend, and is particularly suited to rural and regional students; rather than just watch captured lectures, they can contribute in real time. Although experimentation shows this method of lecture delivery is technically possible, further investigation is required into student preferences, participation levels and achievement in this mode.

\section{NIWB-enhanced video supplemental instruction or tutored video instruction}

Tutored video instruction (TVI) is an alternative mode of lecture delivery where students watch a video recording of a lecture with their co-located peers and a tutor, 
who determines appropriate points to pause the lecture (Gibbons, Kincheloe \& Down, 1977; Martin, Arendale \& Blanc, 1997). This mode of delivery has been used in regional Australian higher education; Martin, et al. (1997) cite the example of first-year degree programs delivered by the Capricornia Institute in the 1980s. It is particularly suited to the Australian higher education context as it can simultaneously provide regional students with access to face to face peer learning opportunities and lectures presented by experts. A further development of the TVI concept was the incorporation of the Supplemental Instruction (SI, known in Australia as Peer Assisted Study Sessions - PASS) peer learning model by Martin and Blanc (1994) to produce Video Supplemental Instruction (VSI). Evaluations of the VSI model that have shown VSI students to outperform their peers in traditional lecture settings, despite having lower tertiary entry scores, however these studies involve non-random assignment (Hurley, Patterson \& Wilcox, 2006; Martin, et al., 1997). In this section the possible use of IWBs and NIWBs in VSI is discussed

VSI provides students with time to think by having them set the pace of the lecture. The IWB allows students to control the video using their hand or whiteboard pen on the board and proceed to annotate the frame. The VSI program incorporates the development of academic skills through role modelling by peers and the facilitator, and the ability to annotate video frames may enhance this. Students can write on the video, which may include visual materials the lecturer is explaining.

In addition to single-site VSI groups, NIWBs can be used to facilitate multi-site sessions. As VSI is suited to small tutorial-size groups, this may be a useful approach when small numbers of students at geographically dispersed sites wish to study elective subjects. In the Deakin at Your Doorstep context, four sites with less than five students per site could participate in a VSI group using NIWBs and video conference facilities. They could view the weekly lecture recordings for an elective unit together and pause or rewind their shared video at any time using the controls on their NIWB. While paused, any student can discuss the lecture content and use any of the annotation or gesture methods the IWB provides. Using this technology to provide a multi-site session may avoid some of the difficulties of supporting SI sessions at remote sites described by Dawson, et al. (2007).

When used in conjunction with existing recordings from a lecture capture system, multi-site VSI delivery using NIWBs is a method of expanding face to face subject delivery with minimal cost. A centralised facilitator can work with students across many sites without the need for the lecturer to redevelop course materials or travel to those sites. Further research into the development and testing of this model is currently underway as part of the Deakin at Your Doorstep project.

\section{Conclusions and future work}

The networked interactive whiteboard (NIWB) offers new capabilities for regional Australian higher education that may help address issues of isolation, academic skills, and peer to peer interaction. This paper has presented a rationale for the use of NIWBs in this setting and exploratory research into their affordances when combined with video conferencing. Three new pedagogies were proposed that are adaptations of existing modes of delivery: a NIWB-enhanced video conference mode; a bridged video conference-web conference mode; and an adaptation of Video Supplemental Instruction and Tutored Video Instruction. Evaluation research into student experiences and 
academic achievement using these new pedagogies is necessary to understand their effectiveness. As networking of IWBs is a relatively under-researched concept, further exploratory research is also necessary to identify other new affordances of NIWBs and the pedagogical approaches they enable. New pedagogies that are suited to regional Australian higher education may enhance the experiences of students and contribute to national goals of increased participation and attainment in higher education.

\section{References}

Bennett, S., Maton, K. \& Kervin, L. (2008). The 'digital natives' debate: A critical review of the evidence. British Journal of Educational Technology, 39(5), 775-786.

Berque, D., Hutcheson, A., Johnson, D., Jovanovic, L., Moore, K., \& Singer, C., et al. (2000). The design of an interface for student note annotation in a networked electronic classroom. Journal of Network and Computer Applications, 23(2), 77-91.

Bradley, D., Noonan, P., Nugent, H. \& Scales, B. (2008). Review of Australian Higher Education: Final Report. Canberra, ACT: Department of Education, Employment and Workplace Relations. http: / / www.deewr.gov.au/highereducation/ review/ pages/reviewofaustralian highereducationreport.aspx

Commonwealth of Australia (2009). Transforming Australia's higher education system. [viewed 20 Jan 2010]. http:/ / www.deewr.gov.au/HigherEducation/Documents/PDF / Additional\%20Report\%20-\%20Transforming\%20Aus\%20Higher\%20ED_webaw.pdf

Dawson, P., Lockyer, L. \& Ferry, B. (2007). Supporting first year student supporters: An online mentoring model for supplemental instruction leaders. In J. Thomas (Ed.), 10th Pacific Rim First Year in Higher Education Conference 2007 - Conference Proceedings. Brisbane: QUT. http: / / www.fyhe.com.au/past_papers / papers07/final_papers / pdfs / 7e.pdf

Freeman, M. (1998). Video conferencing: A solution to the multi-campus large classes problem? British Journal of Educational Technology, 29(3), 197-210.

Gibbons, J., Kincheloe, W. \& Down, K. (1977). Tutored videotape instruction: A new use of electronics media in education. Science, 195(4283), 1139-1146.

Glover, D., Miller, D., Averis, D. \& Door, V. (2005). The interactive whiteboard: A literature survey. Technology, Pedagogy and Education, 14(2), 155-170.

Herbert, S. \& Pierce, R. (2007). Video evidence: What gestures tell us about students' understanding of rate of change. Mathematics: Essential research, essential practice, Proceedings of the 30th annual conference of the Mathematics Research Group of Australasia (pp. 362-371). http: / / www.merga.net.au/documents/RP312007.pdf

Higgins, S., Beauchamp, G., \& Miller, D. (2007). Reviewing the literature on interactive whiteboards. Learning, Media and Technology, 32(3), 213-225.

Hurley, M., Patterson, F., \& Wilcox, F. (2006). Video-based supplemental instruction: Serving underprepared students. In M. E. Stone \& G. Jacobs (Eds.), Supplemental instruction: New visions for empowering student learning (Vol. 106, pp. 43-53). Hoboken, NJ: Wiley.

Kilpatrick, S. \& Bound, H. (2003). Learning online: Benefits and barriers in regional Australia (Vol. 1). Leabrook, South Australia: National Council for Vocational Education Research. [verified 13 Jun 2010] http: / / www.ncver.edu.au/research/proj/nr1F03_1.pdf

Knipe, D. \& Lee, M. (2002). The quality of teaching and learning via videoconferencing. British Journal of Educational Technology, 33(3), 301-311.

Martin, D. (2008). Foreword. Australasian Journal of Peer Learning, 1(1), 3-5. http: / / ro.uow.edu.au / cgi / viewcontent.cgi?article=1001\&context=ajpl 
Martin, D. \& Arendale, D. (1993). Supplemental instruction: Improving first-year student success in high-risk courses. The Freshman Year Experience: Monograph Series (2nd ed., Vol. 7). Columbia, SC: National Resource Center for the First Year Experience and Students in Transition, University of South Carolina. [verified 13 Jun 2010; 1.3 MB] http:/ / www.eric.ed. gov:80/ERICWebPortal/contentdelivery/servlet/ERICServlet?accno=ED354839

Martin, D., Arendale, D. \& Blanc, R. (1997). Mainstreaming of developmental education: Supplemental instruction and video-based supplemental instruction. In H. Levin (Ed.), Alternatives to developmental education. San Francisco: Jossey Bass.

Martin, D. \& Blanc, R. (1994). Video-based supplemental instruction: A pathway to mastery and persistence. In D. Martin \& D. Arendale (Eds.), Supplemental instruction: Increasing achievement and retention (Vol. 60). San Francisco: Jossey Bass.

Mayer, R. (2009). Multimedia learning. Cambridge, UK: Cambridge University Press.

Miller, D. \& Glover, D. (2006). Enhanced secondary mathematics teaching: Gesture and the interactive whiteboard. Paper presented at the British Educational Research Association Annual Conference. [verified 13 Jun 2010] http:/ / www.leeds.ac.uk/educol/documents/161000.doc

Moss, G., Jewitt, C., Levaãiç, R., Armstrong, V., Cardini, A. \& Castle, F. (2007). The interactive whiteboards, pedagogy and pupil performance evaluation: An evaluation of the Schools Whiteboard Expansion (SWE) Project: London Challenge. DfES Research Report 816. London: UK Department for Education and Skills. http: / / publications.dcsf.gov.uk/eOrderingDownload/RR816\%20Report.pdf

Murray, M. (1999). Building networks through peer interaction. Journal of Professional Issues in Engineering Education and Practice, 125(4), 159-162.

Reynolds, F. \& Reeve, R. (2001). Gesture in collaborative mathematics problem-solving. The Journal of Mathematical Behavior, 20(4), 447-460.

Saw, K. G., Majid, O., Ghani, N. A., Atan, H., Idrus, R. M., Rahman, Z. A., et al. (2008). The videoconferencing learning environment: Technology, interaction and learning intersect. British Journal of Educational Technology, 39(3), 475-485.

Smith, H. \& Higgins, S. (2006). Opening classroom interaction: The importance of feedback. Cambridge Journal of Education, 36(4), 485-502.

Smith, H., Higgins, S., Wall, K. \& Miller, J. (2005). Interactive whiteboards: Boon or bandwagon? A critical review of the literature. Journal of Computer Assisted Learning, 21(2), 91-101.

Tinto, V. (1998). Colleges as communities: Taking research on student persistence seriously. Review of Higher Education, 21(2), 167-177.

Topping, K. J. (2005). Trends in peer learning. Educational Psychology, 25(6), 631-645.

Winchester, H. P. M. \& Sterk, B. F. (2006). Multi-campus university management: Lessons from AUQA Audit Reports. Proceedings of the 2006 Australian Universities Quality Forum (pp. 164170). Perth. http:/ / www.auqa.edu.au/auqf/ pastfora/2006/program/paper/paper_a5.pdf

Worthy, A. L., Arul, K. I. \& Brickell, G. (2008). The dynamics of mathematical connection using F2F or video conferencing. In I. Olney, G. Lefoe, J. Mantei \& J. Herrington (Eds.), Proceedings of the Second Emerging Technologies Conference (pp. 206-214). Wollongong, NSW: University of Wollongong. http: / / ro.uow.edu.au / cgi/ viewcontent.cgi?article=1023\&context=etc08

Phillip Dawson, Lecturer in Education Studies

Office of the Pro Vice-Chancellor (Rural and Regional) and School of Education

Deakin University, Warrnambool, Victoria 3280, Australia.

Email: phillip.dawson@deakin.edu.au 